\title{
Gestão de resíduos sólidos urbanos nos municípios da Bacia Hidrográfica do Alto Tietê: uma análise sobre o uso de TIC no acesso à informação governamental
}

\author{
Municipal solid waste management in the municipalities of the Alto Tietê Basin: \\ an analysis of the use of ICT in the access to government information
}

Flávio Bordino Klein ${ }^{[a]}$, Sylmara Lopes Francelino Gonçalves-Dias ${ }^{[0, b]}$, Martin Jayo ${ }^{[c]}$

\footnotetext{
[a] Universidade de São Paulo (USP), Escola de Artes, Ciências e Humanidades (EACH), Programa de Pós-graduação em Sustentabilidade, São Paulo, SP, Brasil

[b] Universidade de São Paulo (USP), Instituto de Energia e Ambiente (IEE), Programa de Pós-graduação em Ciência Ambiental, São Paulo, SP, Brasil

[c] Universidade de São Paulo (USP), Escola de Artes, Ciências e Humanidades (EACH), Programa de Pós-graduação em Gestão de Políticas Públicas, São Paulo, SP, Brasil
}

\section{Resumo}

O estudo teve por objetivo analisar de que forma tecnologias de informação e comunicação (TIC), e a internet em particular, são empregadas para apoiar a gestão de resíduos sólidos urbanos (RSU) no nível municipal. Para tanto, analisaram-se os websites dos 34 municípios da Bacia Hidrográfica do Alto Tietê em relação às informações de programas de coleta seletiva, uso de Pontos de Entrega Voluntária (PEVs) e o acesso ao Plano de Gestão Integrada de Resíduos Sólidos (PGIRS). Os resultados revelam que a maior parte dos municípios utilizam as TIC de forma limitada, e as subutilizam na divulgação de informações relevantes à população, sobretudo no que diz respeito às formas adequadas de separação e acondicionamento dos resíduos sólidos para a coleta seletiva. Isso pode reduzir o desempenho desse serviço público e aumentar os riscos à saúde dos catadores que atuam na reciclagem desses materiais. Concluiu-se que um melhor uso de TIC para o adequado monitoramento e difusão de informações sobre resíduos sólidos urbanos pode ser um mecanismo efetivo para o cumprimento dos objetivos e metas determinados pela Política Nacional de Resíduos Sólidos no nível local e para práticas de accountability e informação aos cidadãos.

Palavras-chave: Tecnologias de informação e comunicação (TIC). Internet. Resíduos sólidos urbanos (RSU). Coleta seletiva. Acesso à informação ambiental.

\section{Abstract}

The research aimed to analyze how information and communication technologies (ICT) and the internet in particular have been applied to support municipal solid waste management (MSW) at the local level. We analyzed the websites of the 34 municipalities that compose the Alto Tietê Basin seeking for information about selective

FBKé gestor ambiental e mestre em Ciências pelo Programa de Pós-graduação em Sustentabilidade da Escola de Artes, Ciências e Humanidades (EACH) da Universidade de São Paulo (USP), e-mail: flabklein@gmail.com

SLFGD é administradora e pedagoga, doutora em Administração de Empresas pela Fundação Getulio Vargas - SP e doutora em Ciência Ambiental pela Universidade de São Paulo, e-mail: sgdias@usp.br

MJ é economista e doutor em Administração de Empresas pela Fundação Getulio Vargas-SP, e-mail: jayomartin@gmail.com 
collection programs, use of voluntary delivery points, and the access to the Integrated Solid Waste Management Plan. The results reveal a limited use of ICT in most municipalities and its misapplication for disseminating important information to the population about adequate procedures of separation and storage of waste for selective collection. This may hinder the effectiveness of this public service and increase the health risks for collectors that work with the recycling of these materials. We conclude that a better use of ICT for an adequate monitoring and dissemination of information about municipal solid waste would be an effective mechanism to enforce the goals and targets determined by the National Solid Waste Policy at the local level, and to enhance the practices of accountability and provision of information to citizens.

Keywords: Information and communication technologies (ICT). Internet. Municipal solid waste (MSW). Selective collection. Access to environmental information.

\section{Introdução}

Os resíduos sólidos urbanos (RSU) constituem hoje um desafiante tema na agenda de políticas públicas ambientais. A gestão e a disposição inadequadas desses resíduos causam conhecidos impactos ambientais e à saúde pública, como poluição e degradação do solo, poluição de corpos d'água e mananciais, intensificação de enchentes devido ao assoreamento de rios e córregos e obstrução de bueiros, proliferação de moscas, baratas, ratos e outros vetores de importância sanitária, aumento no risco de doenças de veiculação hídrica tais como leptospirose e dengue. Há ainda os impactos sociais negativos, como coleta de materiais recicláveis feita em condições insalubres pelos catadores nas ruas, nos galpões de triagem e/ou nas áreas de disposição final, como lixões (Cherfem, 2015; Jacobi \& Besen, 2011; Santos \& Gonçalves-Dias, 2012).

Procurando criar mecanismos legais que possam induzir o poder público a adotar uma gestão adequada dos resíduos sólidos em relação aos aspectos ambientais, sociais, econômicos e sanitários, o governo federal sancionou em 2010 a Política Nacional de Resíduos Sólidos (PNRS), por meio da lei no 12.305 (Brasil, 2010a). Tal política estabelece importantes objetivos, diretrizes e instrumentos, dentre os quais se destaca promover, através de uma abordagem integrada, a redução, reaproveitamento e reciclagem dos resíduos (nessa ordem de prioridade), além da coleta seletiva, a compostagem, a logística reversa, a responsabilidade compartilhada, a educação ambiental, a pesquisa científica e tecnológica, o incentivo e apoio às cooperativas de catadores de materiais recicláveis e o monitoramento e fiscalização ambientais (Brasil, 2010a). Essa abordagem integrada contrapõe-se ao paradigma até então vigente na gestão de resíduos sólidos urbanos, caracterizado por tratar o problema "[...] setorialmente, de forma desarticulada, obstruindo uma visão sistêmica do problema e se refletindo em políticas públicas fragmentadas" (Santos \& GonçalvesDias, 2012, p. 146).

O desafio se verifica até mesmo - ou sobretudo - nas áreas mais desenvolvidas do país. A região da Bacia Hidrográfica do Alto Tietê, por exemplo, cuja área corresponde a 34 dos 39 municípios da Região Metropolitana de São Paulo, apresenta baixa quantidade de resíduos sólidos domésticos encaminhados para a reciclagem através da coleta seletiva quando comparada à quantidade total de resíduos gerados (FUNASA, 2010).

Como apontado pelo Ministério do Meio Ambiente (Brasil, 2010b), para que haja maior desempenho na implantação de programas municipais de coleta seletiva, é fundamental mobilizar e orientar a população, incluindo o uso de meios de comunicação, para que os resultados do programa sejam coerentes com o que foi previsto.

É preciso informar corretamente a população sobre a necessidade de fazer a segregação dos resíduos, acondicioná-los adequadamente para a coleta, cumprir calendários e horários (Brasil, 2010b, p. 50).

Ao mesmo tempo, as tecnologias de informação e comunicação (TIC) têm se apresentado como um instrumento para melhora do desempenho do Estado e das políticas públicas, particularmente como mecanismo de acesso à informação governamental (Brewer et al., 2006; Colombo, 2006; Cunha \& Miranda, 2013). Nesse contexto, é de se esperar que a adoção de estratégias que visem aumentar o desempenho na gestão de resíduos sólidos faça uso dessas tecnologias, seja no 
monitoramento e divulgação de dados e informações que auxiliem o planejamento e gestão governamentais, seja na ampliação do controle e fiscalização sobre os geradores ou ainda na comunicação de informações à população sobre serviços públicos como coleta seletiva e Pontos de Entrega Voluntária (PEVs) em nível local. Com base nessas considerações, o objetivo deste estudo foi analisar de que maneira as TIC vêm sendo utilizadas pelos municípios da Bacia Hidrográfica do Alto Tietê como instrumento de apoio à gestão de resíduos sólidos urbanos.

\section{Resíduos sólidos urbanos: impactos ambientais e estratégias de gestão}

Um dos maiores desafios da atual gestão de resíduos sólidos no Brasil é o de eliminar a disposição final inadequada. A maioria dos municípios brasileiros ainda destina seus resíduos a vazadouros a céu aberto (lixões) e a aterros controlados (forma de disposição também inadequada). Mais de 70\% dos municípios utilizam tais formas inadequadas de disposição final (IBGE, 2010). Como afirmam Santos \& Gonçalves-Dias (2012), essa situação é muito mais crítica nas regiões Norte e Nordeste do Brasil, as quais apresentam as maiores proporções de municípios que destinam resíduos a lixões.

Por outro lado, há inúmeros desafios para acessar dados e informações de RSU junto aos municípios brasileiros. Muitas vezes tais dados são inexistentes ou precários, podendo-se destacar que

[...] as metodologias de pesquisa associadas às divergências de entendimentos entre $o$ entrevistador e o entrevistado, o impasse entre declarar a realidade ou a conveniência, ou até pela má gestão da informação, são questões que merecem atenção, pois o conjunto das informações coletadas constitui o ponto de partida para o planejamento de políticas públicas (Moreira, 2013, p. 25).

Comparando-se os dados de fontes como o Instituto Brasileiro de Geografia e Estatística (IBGE), através da Pesquisa Nacional de Saneamento Básico (PNSB), o Ministério das Cidades, por meio do Sistema Nacional de Informações sobre Saneamento (SNIS), e ainda os dados da Associação Brasileira de Empresas de Limpeza Pública e Resíduos Especiais (ABRELPE), é possível observar diferenças significativas. "Tal fato se deve à adoção de diferentes estratégias metodológicas para a coleta de dados" (Santos \& Gonçalves-Dias, 2012, p. 149). Em relação aos dados anuais publicados por SNIS (2016) e ABRELPE (2014), a Tabela 1 apresenta informações sobre a coleta e disposição final dos RSU em âmbito nacional para o ano base 2014 .

Conforme Chen et al. (2010), é necessária uma padronização nos parâmetros e categorias de resíduos mensurados para permitir o monitoramento e gestão das ações executadas. A comparação das características dos resíduos entre as cidades é muito difícil, sobretudo pela incerteza na precisão e tempestividade na coleta de dados. Mesmo entre os países, não há uma padronização nos critérios para mensurar a geração de resíduos sólidos, e embora muitas definições sobre RSU incluam os resíduos originados nas residências e comércio, outras incluem resíduos de varrição e de limpeza pública e até de origem industrial (Vergara \& Tchobanoglous, 2012).

A destinação dominante (e insustentável) dos resíduos sólidos para aterros é outra problemática importante: “[...] paga-se para 'enterrar' resíduos que, muitas vezes, poderiam ser primeiramente reduzidos, ou então reciclados" (Santos \& Gonçalves-Dias, 2012, p. 150, aspas no original). Conforme apontam Jacobi \& Besen (2006), a Região Metropolitana de São Paulo (RMSP) possui restrições ambientais em 54\% de seu território. A região encontra-se em áreas de proteção aos mananciais, obrigando o transporte dos resíduos para locais muito distantes do ponto de origem, "[...] implicando em custos cada vez maiores para as municipalidades" (Jacobi \& Besen, 2006, p. 95).

Dentre os instrumentos e objetivos da PNRS, a coleta seletiva é um dos aspectos mais relevantes e prioritários. Conforme o art. 9으, § 1o do decreto no 7.404/2010, trata-se de um instrumento essencial para se atingir a meta de disposição final ambientalmente adequada dos rejeitos (Brasil, 2010c). Nesse processo, um dos benefícios diretos da implantação da coleta seletiva e da destinação de resíduos sólidos à reciclagem seria a redução do lixo encaminhado aos aterros sanitários, juntamente com os benefícios da conservação e preservação de recursos e serviços ambientais (Mueller, 2007).

Os principais benefícios sociais propiciados pela coleta seletiva seriam, em especial, relacionados à geração de empregos e renda aos catadores de materiais recicláveis (Cherfem, 2015; FUNASA, 2010). A adoção da coleta seletiva torna-se relevante para gerar melhores condições de trabalho e renda para os catadores, que atuam em $26,8 \%$ dos municípios 
Tabela 1 - Comparativo do panorama de RSU no Brasil

\begin{tabular}{|c|c|c|}
\hline Dados coletados e divulgados & SNIS (2016) & ABRELPE (2014) \\
\hline Municípios Brasil & 5.570 & 5.570 \\
\hline Municípios pesquisados & 3.765 & 400 \\
\hline Participacçoo dos municípios pesquisados & $67,6 \%$ & $7,2 \%$ \\
\hline População total Brasil & 202.799 .518 & 202.799 .518 \\
\hline População total pesquisada & 168.006 .579 & 91.764 .305 \\
\hline Participaçã̃o da população total pesquisada & $82,8 \%$ & $45,3 \%$ \\
\hline Volume de RSU gerado (t/dia) & * & 215.297 \\
\hline Volume de RSU total coletado (t/dia) & $176.400^{\star \star}$ & $195.233^{\star \star}$ \\
\hline Volume de RSU enviado a aterro sanitário (t/dia) & * & $113.975(58,4 \%)$ \\
\hline Volume de RSU enviado a aterro controlado ( $t /$ dia) & * & $47.272(24,2 \%)$ \\
\hline Volume de RSU enviado a lixão (t/dia) & * & $33.986(17,4 \%)$ \\
\hline Volume de RSU enviado a aterro sanitário (t/ano) & $33.485 .574(52,0 \%)$ & * \\
\hline Volume de RSU enviado a aterro controlado (t/ano) & $8.416 .792(13,1 \%)$ & * \\
\hline Volume de RSU enviado a lixão (t/ano) & $8.007 .472(12,4 \%)$ & * \\
\hline Volume de RSU enviado a unidade de triagem (recicláveis) ( $t / a n o)$ & $1.619 .663(2,5 \%)$ & * \\
\hline Volume de RSU enviado a unidade de compostagem (t/ano) & $270.921(0,4 \%)$ & * \\
\hline Volume de RSU sem dados de destinaccão final (†/ano) & $12.627 .463(19,6 \%)$ & * \\
\hline
\end{tabular}

* Sem informaç̃ão; *^Estimativa para todo o território nacional. Fonte: Elaborado pelos autores a partir da ABRELPE (2014) e SNIS (2016).

brasileiros. Conforme aponta a Pesquisa Nacional de Saneamento Básico, do IBGE,

[...] tal atividade é exercida, basicamente, por pessoas de um segmento social marginalizado pelo mercado de trabalho formal, que têm na coleta de materiais recolhidos nos vazadouros ou aterros uma fonte de renda que lhes garante a sobrevivência. (IBGE, 2010, p. 62).

Por fim, ainda haveria os benefícios econômicos gerados pela reciclagem de materiais. Esses benefícios adviriam da diferença entre os custos gerados pela produção de bens a partir de matéria-prima virgem (incluindo os custos de extração e de energia para o processamento) e os custos gerados para a produção dos mesmos bens a partir de material reciclável (IPEA, 2010a).

Se, por um lado, a coleta seletiva é essencial e relevante para diminuir a quantidade de resíduos encaminhados aos aterros, por outro é necessário um planejamento detalhado para a sua efetiva implementação, pois a coleta seletiva tem um custo médio ainda bem elevado no Brasil. Segundo o IPEA (2010a), em âmbito nacional, no ano de 2008, a coleta seletiva estava presente em apenas $18 \%$ dos municípios brasileiros, com um custo médio de R \$ 215,59/tonelada. Esse custo é bastante alto quando comparado ao da coleta convencional (sem segregação entre recicláveis e rejeitos), que seria de $\mathrm{R} \$ 80,24 /$ tonelada, sendo os valores calculados com base no ano de 2007 (IPEA, 2010a).

A gestão integrada de resíduos sólidos baseia-se em diversos princípios que possibilitam a sustentabilidade ambiental, econômica e social. Em virtude da necessária flexibilidade e especificidade das condições locais, a gestão integrada de resíduos não prescreve soluções generalistas: essa visão sistêmica deve basear-se em princípios que permitam o desenvolvimento de soluções adequadas e compatíveis a nível local (Vergara \& Tchobanoglous, 2012). Para alcançá-la torna-se necessário diferenciar três grupos de atores sociais que estão interligados nessa abordagem:

1. as autoridades públicas que estabelecem as políticas públicas para a gestão de resíduos e a tributação da cadeia produtiva; 
2. a população que deve estar ciente dos benefícios da prevenção, da reciclagem e da eliminação de resíduos;

3. o setor privado, através da cadeia de produção, que pode desenvolver estratégias e táticas para administrar o processo de inversão de resíduos recicláveis (Teodósio et al., 2014, p. 237).

No caso brasileiro, as cooperativas de catadores tornam-se um importante elo entre as autoridades públicas, população e o setor privado para a consolidação dessa abordagem integrada. De acordo com Teodósio et al. (2014), o decreto n. 7.404/2010 (que regulamenta a PNRS) tem como um de seus pilares a institucionalização de parcerias municipais ${ }^{1}$ com cooperativas de catadores, processando-se essencialmente pela concessão, por parte das prefeituras municipais, de galpão de triagem, equipamentos e veículos de coleta às cooperativas. Não obstante, nem sempre há garantias de condições dignas de trabalho para aqueles que atuam em cooperativas de reciclagem de RSU (Teodósio et al., 2014).

Nas cidades brasileiras, coleta seletiva, separação e reciclagem de materiais são atividades realizadas, informalmente ou de forma organizada, por meio de associações e cooperativas de catadores. Apesar de o incentivo de inclusão dos catadores ser balizado pela PNRS, a maior parte ainda trabalha de maneira informal e individual na coleta de materiais recicláveis descartados na rua ou, ainda, nos lixões (Cherfem, 2015). A partir de um estudo realizado em seis cooperativas de catadores de materiais recicláveis localizadas em alguns municípios da Região Metropolitana de São Paulo (RMSP), Gutberlet et al. (2016) identificaram alguns fatores de risco de trabalho relatados pelos catadores, que possuem relação direta com a adequada segregação prévia realizada pela população para a coleta seletiva: i) químicos (resíduos nas embalagens, como recipientes de produtos de limpeza tóxicos); ii) biológicos (contato com fungos e bactérias em embalagens contaminadas, sobras de alimentos misturados com materiais recicláveis e infecções devido a vetores transmissores de doenças, como

\footnotetext{
${ }^{1}$ Como forma de facilitar a promoção da coleta seletiva e da inclusão dos catadores, importante marco legal foi estabelecido através do art. 57 da lei no 11.445/2007 (Brasil, 2007) o qual, ao alterar o inciso XXVII do art. 24 da lei no 8.666/93 (Brasil, 1993), passa a dispensar a licitação pública para a inserção dos catadores na coleta seletiva municipal.
}

pombos e ratos); e iii) acidentais (cortes devido a objetos pontiagudos, de vidro, metal, papel e plástico, misturados aos outros materiais). Assim,

[...] na coleta seletiva porta a porta, os catadores ficam expostos a outra situação de risco em função do acondicionamento inadequado dos resíduos pela população. Às vezes, ao recuperarem materiais recicláveis nos sacos de lixo postos na rua pela população, acabam sofrendo cortes nas mãos e nos braços em consequência de objetos perfuro-cortantes também armazenados de forma incorreta [...]. Quanto à qualidade dos materiais coletados, além dos objetos perfuro-cortantes, foi repetidamente mencionado que estes ainda vêm muito sujos, algumas vezes com resíduos de alimentos, expondo os trabalhadores à contaminação biológica e/ou química. (Gutberlet et al., 2016, p. 207, grifo nosso).

De acordo com o Ministério do Meio Ambiente (Brasil, 2010b), para a efetiva execução da coleta seletiva, além de um projeto de coleta e triagem de materiais recicláveis (que inclui a elaboração da setorização e dos roteiros de coleta, definição da localização das unidades de recepção provisória dos resíduos e dos galpões de triagem e escolha de equipamentos de coleta e processamento dos materiais) e de um projeto de inclusão dos catadores (apoio para a execução de atividades de coleta de materiais recicláveis secos domiciliares porta a porta, acesso a atendimento médico e capacitação para o trabalho), é necessário ainda a implantação de um projeto de mobilização social e educação ambiental. Para o MMA (Brasil, 2010b), por meio desse projeto de educação e mobilização seria possível levar o programa de coleta seletiva aos moradores de cada cidade, mostrar a forma de atuação para a coleta dos resíduos gerados em cada domicílio e orientar sobre a correta segregação e acondicionamento dos resíduos.

Essa relevância da educação ambiental, para auxiliar e orientar a população sobre as formas adequadas de segregação dos resíduos sólidos, para posteriormente serem encaminhados à coleta seletiva, reflete a necessidade e a busca de mecanismos para garantir a adequada separação dos recicláveis na fonte geradora. Por essas motivações, as tecnologias de informação e comunicação (TIC), em especial a internet, surgem como potencial nesse processo de 
mobilização da sociedade, e como mecanismos de promoção da educação ambiental.

\section{Governo eletrônico e o acesso à informação}

Governos são atores centrais na rede social dos países e seu uso ou hesitação na adoção de tecnologias de informação e comunicação (TIC) possui implicações sociais relevantes. Embora seja possível apontar críticas à ideia de que o desenvolvimento econômico ou social de um país tem uma relação direta e unívoca com a adoção ou difusão das TIC (Avgerou, 2003), Cunha \& Miranda (2013) ressaltam que essas tecnologias são essenciais pelo seu potencial de catalisadoras e habilitadoras de governança e de práticas democráticas, bem como pelo seu potencial de facilitar o relacionamento entre governo e cidadão, promovendo maior participação, transparência e accountability ${ }^{2}$. Como aponta o IPEA (2010b), uma questão central para a efetividade dos mecanismos de accountability relaciona-se à difusão e acesso à informação:

[...] cidadãos sem informação sobre os processos decisórios e sobre a implementação de políticas não podem reivindicar, de forma satisfatória, mudanças em seus procedimentos e objetivos. Publicizar o que se faz, como se faz e criar canais de contestação integram uma dimensão indispensável para que mecanismos de controle social da administração possam ser efetivos. (IPEA, 2010b, p. 193).

Segundo Cunha \& Miranda (2013), a chamada governança eletrônica - ou e-governança - engloba três dimensões distintas de uso governamental de TIC: e-administração pública, e-serviços públicos e e-democracia. A e-administração refere-se à melhoria dos processos governamentais e do trabalho interno do setor público com a utilização de TIC. Os e-serviços públicos referem-se a novas formas, mediadas por tecnologia, de prestação de serviços aos cidadãos, incluindo o uso de portais governamentais, o uso da internet e outros meios eletrônicos tais como telefone celular, telefone fixo, centrais de atendimento telefônico

\footnotetext{
${ }^{2}$ Accountability é um conceito-chave na moderna gestão pública, funcionando como mecanismo para checar e monitorar o exercício de ministros, gestores, burocratas e agências, no intuito de efetivar a prestação de contas e a responsabilização por atos relativos às suas funções (OECD, 2007).
}

etc. A e-democracia, por fim, envolve a comunicação entre Estado e cidadãos e destes com o Estado no que diz respeito à transparência e à participação ativa do cidadão na elaboração, acompanhamento e controle das políticas públicas. Essa divisão é apenas conceitual, pois embora busque facilitar a compreensão acerca do governo eletrônico, é difícil estabelecer uma fronteira entre essas três dimensões-áreas, uma vez que uma mesma aplicação tecnológica pode ocorrer em uma, duas ou nas três dimensões (Barbosa, 2008; Cunha \& Miranda, 2013).

Colombo (2006) afirma que o uso da internet pode ampliar o acesso democrático do cidadão às decisões, promovendo a transparência das políticas públicas: "Con respecto a las oportunidades, destaca el hecho de que Internet tiene su principal función en ser un elemento de información y comunicación" (Colombo, 2006, p. 33). Da mesma maneira, Brewer et al. (2006) apontam a necessidade de a administração pública adotar as TIC como instrumento de promoção à democracia e melhoria na governança pública: "We believe that public administrators should embrace the information revolution as a means for improving governance and enhancing democratic values" (Brewer et al., 2006, p. 475). Barbosa (2008) menciona a relevância da internet como principal componente do e-gov, ou governo eletrônico, podendo ser considerada a principal força motriz no processo de modernização da administração pública.

Apesar de seu potencial, é importante ressaltar que a internet é apenas um recurso, um instrumento de incentivo à participação e, como outros, também apresenta limitações. As principais seriam a falta de domínio no uso de computadores e softwares de navegação por uma parcela da população e os custos para se ter acesso à internet (Berbel, 2010; Colombo, 2006).

\section{Procedimentos metodológicos}

A coleta de dados foi realizada por meio de uma pesquisa exploratória, de natureza qualitativa. Os 34 municípios da Bacia do Alto Tietê foram selecionados para a análise, dada a adoção dessa Bacia Hidrográfica como unidade de planejamento, conforme o art. 54, X, do decreto $\mathrm{n}^{\circ}$ 7.217/2010 (Brasil, 2010d).

Utilizaram-se como técnicas de coleta de dados a pesquisa documental e a análise documental-eletrônica, 
a partir das informações inerentes aos resíduos sólidos disponíveis nos websites das prefeituras ${ }^{3}$, ao longo do mês de junho de 2015. Para o levantamento e a análise de dados, utilizou-se a pesquisa documental (Calado \& Ferreira, 2005), que compreendeu as etapas descritas a seguir.

Numa primeira etapa, foram analisados os websites de todos os 34 municípios. No caso do Poder Executivo (Prefeitura Municipal), foram consultados sites das secretarias com competência na gestão de resíduos sólidos urbanos, denominadas genericamente como secretarias de meio ambiente, de obras e de serviços urbanos e/ou serviços públicos. Vale ressaltar que não necessariamente todos os municípios possuem essas secretarias. Outra ressalva é que, afora a consulta a tais secretarias, em alguns municípios (como Santo André), consultaram-se também as autarquias municipais responsáveis pela gestão e difusão das informações sobre resíduos sólidos.

Nos casos em que não foi possível obter informações por meio do website do Poder Executivo sobre a existência de programas como coleta seletiva, $\mathrm{PEVs}^{4}$ e o Plano de Gestão Integrada de Resíduos Sólidos (PGIRS), foram consultadas também o website do Poder Legislativo (Câmara Municipal) dos municípios. Nesse caso, acessou-se a aba genericamente intitulada como "leis e decretos" ou "legislação" e inseriram-se as palavras-chave "gestão integrada de resíduos sólidos", "saneamento básico" e "resíduos sólidos".

A partir de tais considerações, analisou-se quais municípios tinham:

i. Plano de Gestão Integrada de Resíduos Sólidos (PGIRS), conforme lei no 12.305/10;

ii. Serviço público de coleta seletiva realizada porta a porta; $\mathrm{e}$

iii. Serviço público através da oferta de Pontos de Entrega Voluntária (PEVs) para os seguintes resíduos: recicláveis (domésticos), resíduos da

\footnotetext{
${ }^{3} \mathrm{O}$ website do município de Cotia foi o único que esteve indisponível para a consulta durante o período da pesquisa.

${ }^{4}$ A respeito dos Pontos de Entrega Voluntária (PEVs), a norma brasileira NBR 15.112 (ABNT, 2004) define-os como locais públicos para o descarte de resíduos de construção civil, volumosos (como colchões, sofás e móveis em geral), resíduos da coleta seletiva e resíduos enquadrados na logística reversa obrigatória, para posteriormente serem destinados de forma ambientalmente correta (Brasil, 2012a).
}

construção civil, resíduos volumosos, óleo de cozinha, pneus, lâmpadas (fluorescentes, de vapor de sódio e mercúrio e luz mista), pilhas e baterias, embalagens de óleos lubrificantes e eletroeletrônicos.

Assim, identificados esses atributos, passou-se para a segunda etapa, relacionada à coleta e tratamento dos dados. Foi utilizado um procedimento de análise de conteúdo (Appolinário, 2011), partindo-se de uma definição operacional para cada conceito ou variável relacionada aos serviços e informações disponibilizados no website, conforme Quadro 1. Os municípios sem PGIRS, programas de coleta seletiva ou PEVs não foram incluídos nessa análise.

Por fim, a terceira e última etapa foi categorizar, qualitativamente, a acessibilidade das informações disponibilizadas pelos municípios em três níveis:

i. Nível alto: informações claras e de fácil acesso através do portal da prefeitura, incluindo o acesso ao PGIRS e procedimentos relacionados à coleta seletiva e PEVs;

ii. Nível médio: informações parcialmente divulgadas para procedimentos sobre coleta seletiva e PEVs, podendo apresentar dificuldades na navegação pelo portal para acesso ao PGIRS;

iii. Nível baixo: não há informações sobre procedimentos para coleta seletiva, PEVs e alta dificuldade na navegação do site e na consulta às secretarias e órgãos competentes. Informações apenas por notícia, fragmentadas, obtidas apenas por busca de palavras-chave no portal ("coleta seletiva”, "gestão integrada”, "entulhos”, "ecoponto" e "resíduos sólidos").

\section{Caracterização da gestão de resíduos sólidos urbanos nos municípios da Bacia do Alto Tietê e o acesso à informação}

De uma forma geral, a grande maioria dos municípios da Bacia Hidrográfica do Alto Tietê não praticam a disponibilização de informações sobre resíduos sólidos na internet, ou o fazem de forma extremamente precária, como se pode constatar pelo baixo grau de acessibilidade à informação retratado no Quadro 2. Essa é uma questão relevante, pois informações básicas como orientar o cidadão sobre 
quais tipos de resíduos devem ser destinados à coleta seletiva, as formas de separá-los e acondicioná-los terão implicação direta no nível de desempenho da reciclagem desses materiais segregados. Além disso, as variáveis relacionadas ao custo dos serviços e desempenho dos programas e serviços ofertados à população não puderam ser avaliadas, pois nenhum dos municípios possui essas informações disponíveis no portal eletrônico.

Brewer et al. (2006) apontam que o site ou portal eletrônico governamental deve ser desenhado como uma ferramenta efetiva para tornar as informações disponíveis o quanto possível ao cidadão comum, possibilitando-o a acessar a internet e obter as informações necessárias de seu interesse. Como afirmam Barciotte \& Saccaro (2012), embora muitos municípios utilizem canais eletrônicos como os sites governamentais para difundir informações objetivas para ações relacionadas aos resíduos sólidos, na maioria dos casos essas informações para a população são incompletas ou insuficientes.

As informações sobre quais resíduos são recicláveis, isto é, que podem ser separados para a coleta seletiva (conforme item 2 do Quadro 2) são divulgados apenas por São Paulo, Santo André, Embu das Artes, Guarulhos e São Bernardo do Campo. Os resíduos sólidos domésticos gerados pela população incluem materiais comumente destinados à reciclagem como metais, aço, alumínio, papel, papelão, tetrapak, plástico (mole e rígido) e vidro, os quais correspondem a aproximadamente 31,9\% do volume total (Brasil, 2012a; CEMPRE, 2010). 0 baixo número de municípios que informam ao menos o que pode/não pode ser separado para coleta seletiva pode reduzir o desempenho desse serviço público, aumentando a quantidade de rejeitos e a assimetria da informação à população. As informações sobre formas adequadas de separação e acondicionamento dos resíduos sólidos (itens 3 e 4 do Quadro 2) são relevantes para auxiliar

Quadro 1 - Informaç̃̃es sobre os resíduos sólidos urbanos (RSU) pesquisadas nos portais das prefeituras e definiç̃oes operacionais usadas para mensurá-las qualitativamente

\begin{tabular}{|c|c|}
\hline $\begin{array}{l}\text { Variáveis e conceitos } \\
\text { pesquisados sobre os RSU }\end{array}$ & Definição operacional (informação buscada) \\
\hline Custo da coleta seletiva & RS/tonelada de resíduos sólidos coletados através da coleta seletiva \\
\hline Desempenho da coleta seletiva & Percentual ou quantidade da massa de resíduos sólidos domésticos destinados à reciclagem em relação à massa total \\
\hline População atendida pelo serviço de coleta seletiva & Número ou percentual da população do município atendida pela coleta seletiva em relação à população total \\
\hline Orientaç̃oes aos usuários para coleta seletiva e uso dos PEVs & $\begin{array}{l}\text { - Procedimentos relacionados à separação e acondicionamento dos resíduos; - Tipos de resíduos passíveis de } \\
\text { segregação; } \\
\text { - Locais, bairros atendidos e horário de funcionamento }\end{array}$ \\
\hline
\end{tabular}

Fonte: Elaborado pelos autores.

Quadro 2 - Análise qualitativa das informações e serviços sobre coleta seletiva

\begin{tabular}{|c|c|c|}
\hline $\begin{array}{l}\text { Procedimentos sobre atendimento } \\
\text { do serviço, formas de separação e } \\
\text { acondicionamento dos resíduos }\end{array}$ & $\begin{array}{l}\text { Grau de acesso à } \\
\text { informação }\end{array}$ & Município \\
\hline \multirow{3}{*}{$\begin{array}{l}\text { Informações disponíveis sobre: } \\
\text { - dias, horários e bairros atendidos (1); } \\
\text { - quais resíduos são recicláveis (2); } \\
\text { - como separá-los e acondicioná-los (3); } \\
\text { - cuidados com vidros e materiais cortantes (4) }\end{array}$} & Alto & São Paulo (1, 2 e 3); Santo André (1, 2, 3 e 4) \\
\hline & Médio & $\begin{array}{l}\text { Barueri (1); Embu das Artes (1 e 2); Guarulhos (1 e 2); Mogi das Cruzes (1); São Bernardo do } \\
\text { Campo (2); nenhum dos municípios (itens } 3 \text { e 4) }\end{array}$ \\
\hline & Baixo & $\begin{array}{l}\text { Arujá; Carapicuíba; Diadema; Ferraz de Vasconcelos; Itapecerica da Serra; Jandira; Mauá; Osasco; } \\
\text { Poá; Ribeirão Pires; Santana de Parnaíba; São Caetano do Sul; Salesópolis; Suzano: nenhum } \\
\text { desses municíios contemplam informações dos itens } 1 \text { ao } 4\end{array}$ \\
\hline
\end{tabular}

Fonte: Elaborado pelos autores. 
em aspectos relacionados, por exemplo, à necessidade de remover restos de alimento das embalagens, ao local em que os resíduos devem ser armazenados até a coleta, ou aos cuidados especiais com materiais cortantes, como vidros. Não obstante, apenas São Paulo e Santo André disponibilizam algumas dessas informações. Acerca dos cuidados com materiais cortantes, a informação é prestada apenas pelo último.

O grupo dos municípios com divulgação de informações baixa ou inexistente é bem significativo. Reúne 14 dos 21 municípios identificados na pesquisa, os quais, embora possuam o serviço de coleta seletiva, disponibilizam poucas e dispersas informações, obtidas apenas inserindo-se palavras-chave, por algumas notícias existentes no portal e por consulta ao PGIRS. Em comum, esses municípios não possuem uma aba específica no portal eletrônico sobre o órgão competente pela execução desse serviço, quais bairros são atendidos e quais tipos de resíduos devem ser separados e acondicionados. Mesmo sendo cidades de médio ou grande porte, não há uma adoção da internet como instrumento tecnológico para difundir informações sobre a coleta seletiva e demais programas e ações relacionadas aos resíduos sólidos.

A inadequada separação e acondicionamento dos resíduos sólidos por parte da população pode implicar, ao menos, dois problemas: baixa eficiência da coleta seletiva e riscos na rotina de trabalho e na saúde dos catadores. Estimativas indicam que a participação dos resíduos recuperados pelos programas de coleta seletiva formal ainda é muito pequena em relação ao total coletado, o que indica que a reciclagem no país ainda é mantida pela coleta pós-consumo informal realizada, sobretudo, pelos catadores de materiais recicláveis (IPEA, 2012). Na cidade de São Paulo, Santos \& Gonçalves-Dias (2012) apontam a fragilidade desse tipo de programa: "[...] nem $1 \%$ do total de resíduos gerados diariamente em São Paulo é efetivamente encaminhado para a reciclagem" (Santos \& Gonçalves-Dias, 2012, p. 152).

Essa baixa eficiência da coleta seletiva e reciclagem não é exclusiva do município de São Paulo. Jacobi \& Besen (2006) já identificavam um elevado índice de rejeitos de materiais recicláveis ${ }^{5}$ entre alguns municípios da Região Metropolitana de São Paulo:

\footnotetext{
${ }^{5}$ Cálculo feito entre a diferença da quantidade inicial de resíduos da coleta seletiva encaminhado à reciclagem pela quantidade final de resíduos efetivamente comercializado pelas cooperativas de catadores.
}

Barueri (13,3\%), Diadema (18,5\%), Embu das Artes (16,1\%), Itapecerica da Serra (5\%), Poá (8\%), Santana de Parnaíba (35\%), Santo André (50\%) e São Paulo $(28,6 \%)$ (Jacobi \& Besen, 2006). Tais índices, apesar de não serem recentes, apontam para a relevância na adoção de estratégias integradas para aumentar o desempenho da coleta seletiva através da difusão de informações necessárias à população. Se parte dos resíduos separados é imprópria para a reciclagem, isso implica aumento de custos para a municipalidade e menor desempenho e rentabilidade no processamento e segregação desse material pelos catadores. Como ressaltado por Cherfem (2015), a precariedade do trabalho e geração de renda dos catadores incluem variáveis como preços baixos, exploração das indústrias e atravessadores e exposição e contato com resíduos perigosos e contaminados com sobras de alimentos, que ocasionam mau cheiro e perda da produtividade dos materiais comercializados.

A prevenção de riscos de acidentes de trabalho entre catadores tem relação direta com a segregação prévia dos resíduos pela população. De acordo com Jacobi \& Besen (2006, p. 98), 19 entre 31 organizações de catadores de materiais recicláveis relataram a ocorrência de acidentes, sendo esses resultantes na maioria de cortes por vidro. Apesar de praticamente todas as organizações entrevistadas terem afirmado que utilizavam luvas,

[...] constata-se uma incidência significativa de acidentes de trabalho causados por cortes e pela falta de uso adequado de EPIs, o que indica uma provável falha de orientação para o uso do equipamento (Jacobi; Besen, 2006, p. 98).

Independente da relação causal ou não entre o uso inadequado de luvas e os acidentes por cortes com vidro, esse elevado índice de acidentes revela a importância da adequada segregação e acondicionamento dos resíduos por parte da população, com especial atenção ao cuidado com materiais cortantes que, com exceção de Santo André, não são informados pelos municípios analisados.

Tal situação também foi identificada por Gutberlet et al. (2016), ao afirmarem que a entrada do material coletado nas cooperativas é considerada pelos catadores como uma etapa com risco para a saúde, em função da recepção de muitos materiais sujos e cortantes. Afora a perda de produtividade e os riscos de acidentes por cortes com vidro, é relevante apontar os riscos de 
transmissão de doenças por contaminação e baixa qualidade dos resíduos separados pela população. Além disso, os autores apontam:

[...] a presença de ratos, pombos e insetos como um sério problema, pois estão em grande quantidade nas cooperativas e podem ser vetores de doenças. As autoridades locais de saúde estão conscientes do problema e constantemente realizam ações para reduzir as infestações. Porém, as causas principais dessa situação são a contaminação dos recicláveis na fonte - ou seja, a falta de uma separação limpa dos materiais entre recicláveis, orgânicos e de descarte na residência - , como também a má organização do trabalho e a ausência ou escassez de ações governamentais. A educação ambiental continuada da população é uma necessidade para garantir a adequada separação e o preparo dos recicláveis na fonte geradora (Gutberlet et al., 2016, p. 210-211).

Em relação à oferta de PEVs para resíduos da construção civil (RCC), conforme Quadro 3, a pesquisa identificou que apenas os municípios de Guarulhos, Mauá, Mogi das Cruzes, São Bernardo do Campo, São Paulo e Santo André ofertam esse tipo de serviço à população. Os municípios de Mogi das Cruzes e Santo André são os únicos municípios que contemplam ações relacionadas à coleta seletiva, RCC e para alguns dos resíduos enquadrados na logística reversa, apresentando alto nível de informações sobre o uso desses equipamentos públicos.

Os municípios de Guarulhos, Mauá, São Bernardo do Campo e São Paulo possuem, em comum, programas de coleta seletiva e gerenciamento de RCC através dos PEVs, sendo uma ação relevante, pois esses resíduos são os que mais causam impactos ambientais decorrentes do despejo irregular e também representam a massa predominante de resíduos sólidos urbanos. Apenas Mauá possui gerenciamento para alguns resíduos enquadrados na logística reversa (embora apresente nível baixo de divulgação das informações sobre os serviços, conforme Quadro 3).

Chama a atenção o baixo número de municípios que ofertam PEVs para resíduos da construção civil (apenas 6 dos 34 municípios da Bacia do Alto Tietê). O Ministério do Meio Ambiente (Brasil, 2012b) recomenda que esses equipamentos públicos devem recepcionar também os resíduos domésticos secos para coleta seletiva, resíduos volumosos e resíduos enquadrados na logística reversa obrigatória. Os resultados do Quadro 3 demonstram a baixa adesão

Quadro 3 - Análise qualitativa das informações e serviços sobre a oferta dos PEVs

\begin{tabular}{|c|c|c|c|}
\hline $\begin{array}{l}\text { Atendimento do } \\
\text { serviço, formas } \\
\text { de separação, } \\
\text { acondicionamento e } \\
\text { procedimentos para } \\
\text { descarte }\end{array}$ & $\begin{array}{l}\text { Tipo de resíduo } \\
\text { coletado }\end{array}$ & $\begin{array}{l}\text { Grau de acesso } \\
\text { à informação }\end{array}$ & Municípios \\
\hline Informaç̄oes disponíveis sobre: & \multirow{6}{*}{$\begin{array}{l}\text { - RCC (A) } \\
\text { - Volumosos (B) } \\
\text { - Recilláveis (C) } \\
\text { - Óleo de cozinha (D) } \\
\text { - Pneus (E) } \\
\text { - Lâmpadas (F) } \\
\text { - Pilhas e baterias (G) } \\
\text { - Embalagens de óleo lubrificante (H) } \\
\text { - Eletroeletrônicos (I) }\end{array}$} & \multirow{4}{*}{ Alto } & $\begin{array}{l}\text { - Guarulhos: (1, } 2,3 \text { e 4); tipos de residuos coletados: } \\
\text { A, B e C }\end{array}$ \\
\hline - endereço dos locais (1); & & & $\begin{array}{l}\text { - Mogi das Cruzes: (1, 2, } 3 \text { e 4); tipos de resíduos } \\
\text { coletados A, B, C, D, E e l }\end{array}$ \\
\hline \multirow{3}{*}{$\begin{array}{l}\text { - horário de atendimento (2); } \\
\text { - materiais que podem ser descartados (3); }\end{array}$} & & & $\begin{array}{l}\text { - Santo André: (I, 2, 3 e 4); itipos de resíduos } \\
\text { coletados: A, B, C, D, E, F, G, e I }\end{array}$ \\
\hline & & & $\begin{array}{l}\text { - São Paulo: (1, } 2,3 \text { e 4); tipos de resíduos coleta- } \\
\text { dos: A, B e C }\end{array}$ \\
\hline & & Médio & $\begin{array}{l}\text { - São Bernardo do Campo: (1, } 3 \text { e 4); tipos de } \\
\text { resíduos coletados A, B e C }\end{array}$ \\
\hline - restriç̄os de limite/descarga (4) & & Baixo & - Maú: (1); tipos de resíduos coletados: A, B, D, F e G \\
\hline
\end{tabular}

Fonte: Elaborado pelos autores. 
dessas recomendações mesmo nos municípios que ofertam esse tipo de equipamento à população.

Quanto aos municípios que possuem o PGIRS (totalizavam 10 dos 34 municípios da Bacia do Alto Tietê), verificou-se nos websites municipais que há significativas diferenças em termos de acessibilidade ao se navegar pelos portais eletrônicos. Nos municípios de Guarulhos, Mogi das Cruzes, São Paulo e Santo André, o acesso ao PGIRS foi realizado consultando-se as secretarias e/ou autarquias municipais competentes, $\mathrm{e}$ em São Caetano do Sul através da consulta da legislação, que possui uma aba no portal com acesso direto ao plano. Em comum, para esses municípios não houve a necessidade de utilizar palavras-chave na pesquisa pelo portal. Já para os municípios de Diadema, Embu das Artes, Salesópolis, Santana de Paranaíba e Suzano notou-se grande dificuldade para se obter acesso ao plano, sendo necessário o uso de mecanismos de pesquisa e busca por palavras-chave no portal municipal: nenhuma das secretarias consultadas disponibilizava uma aba específica e de fácil acesso para download do aludido documento.

\section{Considerações finais}

Este estudo considera que a adoção de TIC associadas ao governo eletrônico pode ampliar a efetividade das políticas públicas em torno da gestão de resíduos sólidos. Sob a óptica governamental, a problemática requer o uso de inovações e mecanismos tecnológicos para minimizar os impactos ambientais e sociais negativos e, ainda, a necessária divulgação de dados e informações ambientais como garantia para maior participação democrática.

Com base nos critérios do Quadro 1, verificou-se que a maior parte dos municípios não possuem dados e informações suficientes e adequados acerca da gestão de resíduos sólidos urbanos dentro de sua esfera de competência administrativa; apresentam pouca transparência nos programas e ações; e não disponibilizam informações sobre custos e desempenho desses programas à municipalidade. Configura-se, assim, um uso limitado de TIC no relacionamento com o cidadão. Com exceção de São Paulo e Santo André, a grande maioria dos municípios apresentou um baixo nível de divulgação de informações sobre a coleta seletiva, incluindo os tipos de resíduos que devem ser segregados e as formas de acondicionamento, o que pode comprometer o desempenho desse serviço público.

Enfatiza-se que os dados sobre os resíduos sólidos são base para que o gestor municipal possa executar a prestação dos serviços públicos inerentes aos RSU de maneira eficiente, atendendo os objetivos, instrumentos e planos de gestão integrada de resíduos. Em conformidade com o Plano Nacional de Resíduos Sólidos (Brasil, 2012a), um dos instrumentos previstos é exatamente o Sistema Nacional de Informações sobre a Gestão de Resíduos Sólidos (SINIR). 0 Sistema tem como objetivo a disponibilização de estatísticas e indicadores visando caracterizar demanda e oferta de serviços públicos de gestão e gerenciamento de resíduos sólidos, de modo a permitir seu contínuo monitoramento. "Dentre os indicadores de resíduos sólidos já propostos pelo SINISA, deverão ser selecionados e integrados pelo SINIR aqueles que traduzem com maior clareza a eficiência da gestão municipal" (Brasil, 2012a, p. 48, grifo nosso). Logo, os critérios do Quadro 1 (incluindo os custos, população atendida e desempenho dos serviços) deveriam ser monitorados e difundidos no website dos municípios, para que possam ser integrados e centralizados no SINIR, de competência do governo federal.

Além disso, ao não se adotar suficientemente os preceitos da transparência pública e da governança eletrônica perde-se a oportunidade de difundir a responsabilidade compartilhada, deixando-se de promover a divulgação de informações que tornariam o cidadão mais sensibilizado e ciente do seu papel na promoção do desenvolvimento sustentável e da preservação do meio ambiente.

0 acesso a dados e informações ambientais, apesar de ser determinado pela Política Nacional de Meio Ambiente e pela Política Nacional de Resíduos Sólidos, e apesar de imprescindível à accountability, não vem sendo fomentado com a intensidade necessária na maior parte dos municípios da Bacia do Alto Tietê. Se tomarmos apenas o serviço público de coleta seletiva, a falta de informação adequada à população sobre as formas de separação e acondicionamento pode comprometer o desempenho da execução desse serviço pela grande geração de rejeitos encaminhados aos aterros. Ainda, o descarte incorreto desses resíduos, misturados com materiais cortantes como vidro, está diretamente relacionado aos acidentes de trabalho que ocorrem com os coletores (garis) e também com os catadores que atuam nas cooperativas de reciclagem. Embora 
o objeto desta pesquisa tenha sido o uso de TIC e em específico da internet para a melhora da gestão de resíduos sólidos, o baixo número de municípios que possuem o PGIRS, a oferta de PEVs e mesmo da coleta seletiva e, ainda, a falta ou dificuldade na obtenção de informações revelam a complexidade dos desafios que se colocam aos municípios para fazer frente às ações em ordem hierárquica determinadas pela Política Nacional de Resíduos Sólidos: reduzir, reaproveitar e reciclar. As TIC, em conjunto com o monitoramento e elaboração de indicadores, a ampliação do acesso à informação, a promoção de ações como a compostagem de resíduos orgânicos e a orientação sobre o adequado descarte de resíduos especiais, como resíduos da construção civil, medicamentos e antibióticos fora do prazo de validade e os vinculados à logística reversa obrigatória, representam apenas alguns dos muitos desafios que já deveriam ser parte da agenda dos governos locais, como um esforço de alcance à efetividade na implementação dessa política pública de nível nacional.

\section{Referências}

Appolinário, F. (2011). Metodologia da ciência: filosofia e prática da pesquisa. São Paulo: Cengage Learning.

Associação Brasileira das Empresas de Limpeza Pública e Resíduos Especiais - ABRELPE. (2014). Panorama dos resíduos sólidos do Brasil. São Paulo: ABRELPE. Recuperado de http://www.abrelpe.org.br/panorama_envio.cfm?ano=2014

Associação Brasileira de Normas Técnicas - ABNT. (2004). NBR15.112: resíduos da construção civil e resíduos volumosos: áreas de transbordo e triagem: diretrizes para projeto, implantação e operação. Rio de Janeiro: ABNT.

Avgerou, C. (2003). The link between ICT and economic growth in the discourse of development. In M. Korpela, R. Montealegre, \& A. Poulymenakou (Eds.), Organizational information systems in the context of globalization (pp. 373-386). New York: Springer. http://dx.doi. org/10.1007/978-0-387-35695-2_23.

Barbosa, A. F. (2008). Governo eletrônico: dimensões da avaliação de desempenho na perspectiva do cidadão (Tese de doutorado), FGV- EAESP, São Paulo.

Barciotte, M. L., \& Saccaro, N. L., Jr. (2012). Sensibilização e mobilização dentro da Política Nacional de Resíduos Sólidos: desafios e oportunidades da educação ambiental (Texto para Discussão). Brasília: IPEA.
Berbel, D. B. (2010). Participação pública em ciência e tecnologia através de mecanismos de governo eletrônico: uma proposta metodológica de avaliação. In V. Miotello, \& W. A. M. Hoffmann (Eds.), Apontamentos de estudos sobre Ciência, Tecnologia \& Sociedade (pp. 115-128). São Carlos: Pedro \& João Editores.

Brasil. (1993, 21 de junho). Lei no 8666, de 21 de junho de 1993. Regulamenta o art. 37, inciso XXI, da Constituição Federal, institui normas para licitações e contratos da Administração Pública e dá outras providências. Brasília: Diário Oficial da União, seção 1, p. 8269.

Brasil. (2007, 5 de janeiro). Lei no 11.445, de 5 de janeiro de 2007. Estabelece diretrizes nacionais para o saneamento básico; altera as Leis $n^{\circ}$ S 6.766, de 19 de dezembro de 1979, 8.036, de 11 de maio de 1990, 8.666, de 21 de junho de 1993, 8.987, de 13 de fevereiro de 1995; revoga a Lei no 6.528, de 11 de maio de 1978; e dá outras providências. Brasília: Diário Oficial da União, seção 1, p. 3.

Brasil. (2010a, 3 de agosto). Lei no 12.305, de 2 de agosto de 2010. Institui a Política Nacional de Resíduos Sólidos; altera a Lei no 9.605, de 12 de fevereiro de 1998; e dá outras providências. Brasília: Diário Oficial da União, seção 1, p. 3.

Brasil. Ministério do Meio Ambiente - MMA. (2010b). Manual para implantação de compostagem e de coleta seletiva no âmbito de consórcios públicos. Brasília: MMA. Recuperado de http://www.mma.gov.br/estruturas/ srhu_urbano/_arquivos/3_manual_implantao_compostagem_ coleta_seletiva_cp_125.pdf

Brasil. (2010c, 23 de dezembro). Decreto $n^{-}$7.404, de 23 de dezembro de 2010. Regulamenta a Lei n. 12.305, de 2 de agosto de 2010, que institui a Política Nacional de Resíduos Sólidos, cria o Comitê Interministerial da Política Nacional de Resíduos Sólidos e o Comitê Orientador para a Implantação dos Sistemas de Logística Reversa, e dá outras providências. Brasília: Diário Oficial da União, seção 1, edição extra, p. 1.

Brasil. (2010d, 22 de junho). Decreto $n^{\circ}$ 7.217, de 21 de junho de 2010. Regulamenta a Lei $n .11 .445$, de 5 de janeiro de 2007, que estabelece diretrizes nacionais para o saneamento básico e dá outras providências. Brasília: Diário Oficial da União, seção 1, edição extra, p. 1.

Brasil. (2012a). Plano nacional de resíduos sólidos. Brasília: Ministério do Meio Ambiente.

Brasil. Ministério do Meio Ambiente - MMA. (2012b). Planos de gestão de resíduos sólidos: manual de orientação. Brasília: MMA. Recuperado de http://www.mma.gov.br/ estruturas/253/_publicacao/253_publicacao09042012101719. pdf 
Brewer, G. A., Neubauer, B. J., \& Geiselhart, K. (2006). Designing and implementing e-government systems: critical implications for public administration and democracy. Administration \& Society, 38(4), 472-499. http://dx.doi. org/10.1177/0095399706290638.

Calado, S., \& Ferreira, S. C. (2005). Análise de documentos: método de recolha e análise de dados. Lisboa: Universidade de Lisboa.

Chen, X., Geng, Y., \& Fujita, T. (2010). An overview of municipal solid waste management in China. Waste Management, 30(4), 716-724. http://dx.doi.org/10.1016/j. wasman.2009.10.011.

Cherfem, C. O. (2015). A coleta seletiva e as contradições para a inclusão de catadoras e catadores de materiais recicláveis: construção de indicadores sociais. Mercado de trabalho, (59), 89-98.

Colombo, C. (2006). Innovación democrática y TIC: ¿Hacia una democracia participativa? Revista de Estudios de Derecho y Ciencia Política, 3, 28-38.

Compromisso Empresarial para Reciclagem - CEMPRE. (2010). Lixo municipal: manual de gerenciamento integrado (3. ed.). São Paulo: CEMPRE.

Cunha, M. A. V. C., \& Miranda, P. R. M. (2013). 0 uso de TIC pelos governos: uma proposta de agenda de pesquisa a partir da produção acadêmica e da prática nacional. Organizações \& Sociedade, 20(66), 543-566. http://dx.doi. org/10.1590/S1984-92302013000300010.

Fundação Nacional de Saúde - FUNASA. (2010). Programas municipais de coleta seletiva de lixo como fator de sustentabilidade dos sistemas públicos de saneamento ambiental na região metropolitana de São Paulo. Brasília: FUNASA.

Gutberlet, J., Baeder, A. M., Pontuschka, N. N., Felipone, S. M. N., Santos, T. L. F., \& Souza, A. M. (2016). Pesquisa-ação em educação ambiental e saúde dos catadores: estudo de caso realizado com integrantes de cooperativas de coleta seletiva e reciclagem na Região Metropolitana de São Paulo. In B. C. J. Pereira, \& F. L. Goes (Eds.), Catadores de materiais recicláveis: um encontro nacional (pp. 201-216). Rio de Janeiro: Ipea.

Instituto Brasileiro de Geografia e Estatística - IBGE. (2010). Pesquisa nacional de saneamento básico 2008. Rio de Janeiro: IBGE.

Instituto de Pesquisa Econômica Aplicada - IPEA. (2010a). Pesquisa sobre pagamento por serviços ambientais urbanos para gestão de resíduos sólidos. Brasília: IPEA. Relatório de pesquisa. Recuperado de http://www.ipea.gov.br/portal/ index.php?option=com_alphacontent\&view=alphaconten t\&Itemid=365

Instituto de Pesquisa Econômica Aplicada - IPEA. (2010b). Estado, instituições e democracia: democracia (Vol. 2, pp. 185-210). Brasília: IPEA. Recuperado de http://www.ipea. gov.br/portal/index.php?option=com_alphacontent\&view $=$ alphacontent\&Itemid=358

Instituto de Pesquisa Econômica Aplicada - IPEA. (2012). Plano nacional de resíduos sólidos: diagnostico dos resíduos urbanos, agrosilvopastoris e a questão dos catadores (Comunicado IPEA, Vol. 145). Brasília: IPEA. Relatório de Pesquisa.

Jacobi, P. R., \& Besen, G. R. (2006). Gestão de resíduos sólidos na Região Metropolitana de São Paulo: avanços e desafios. São Paulo em Perspectiva, 20(2), 90-104.

Jacobi, P. R., \& Besen, G. R. (2011). Gestão dos resíduos sólidos em São Paulo: desafios da sustentabilidade. Estudos Avançados, 25(71), 135-158. http://dx.doi.org/10.1590/ S0103-40142011000100010.

Moreira, M.C. (2013). Dados e informações sobre resíduos sólidos urbanos no Brasil (Dissertação de mestrado). Rio de Janeiro: Escola Nacional de Saúde Pública Sergio Arouca.

Mueller, C. C. (2007). Os economistas e as relações entre o sistema econômico e o meio ambiente. Brasília: Universidade de Brasília, Finatec.

Organisation for Economic Co-Operation and Development - OECD. (2007). OECD glossary of statistical terms. Paris: OECD. Recuperado de http://stats.oecd.org/glossary

Santos, M. C. L., \& Gonçalves-Dias, S. L. F. (2012). Gestão de Resíduos na cidade de São Paulo: um problema, múltiplas soluções. In B. R. Padovano, M. Namur, \& P. B. Sala (Eds.), São Paulo: em busca da sustentabilidade (Vol. 1, pp. 146-159). São Paulo: EDUSP/PINI.

Sistema Nacional de Informações sobre Saneamento - SNIS. (2016). Diagnóstico do manejo de resíduos sólidos urbanos: 2014. Brasília: Ministério das Cidades. Recuperado de http://www.snis.gov.br/

Teodósio, A. S. S., Gonçalves-Dias, S. L. F., \& Santos, M. C. L. (2014). Reciclagem no Interstício das Relações Intersetoriais: a Política Nacional de Resíduos Sólidos e os desafios para 
a inclusão social e produtiva dos catadores. In M. C. L. Santos, S. Walker, \& S. L. F. Gonçalves-Dias (Eds.), Design, resíduo \& dignidade (pp. 231-268). São Paulo: Olhares.

Vergara, S. E., \& Tchobanoglous, G. (2012). Municipal solid waste and the environment: a global perspective. Annual
Review of Environment and Resources, 37(1), 277-309. http:// dx.doi.org/10.1146/annurev-environ-050511-122532.

Recebido: Set. 07, 2016

Aprovado: Mar. 21, 2017 